\title{
New Thoughts on College Counselors' In-Depth Counseling Work in Student Development Guidance in the Information Age
}

\author{
Tingting Luo
}

\author{
School of Electronic Science and Engineering, University of Electronic Science and Technology of \\ China, Sichuan 610054, China
}

\begin{abstract}
The study and development of college students is an important part of the cultivation of university talents. The in-depth counseling of counselors in the development of students is an important way to develop talents and is widely used in the field of education. Its unique significance and connotation are constantly affirmed. In the information age, various Internet platforms have imperceptibly influenced the thinking of contemporary young students, the diversity of educational channels, and the complexity of information. It has facilitated the development of university students and is a challenge. College counselors need to actively explore the new path of in-depth counseling in the information age, so that in-depth counseling can better guide the development of students, implement the fundamental tasks of talent training, help students better adapt to university life, and complete their career planning.
\end{abstract}

Keywords: Information age; student development guidance; college students.

\section{Introduction}

The information age has brought about tremendous changes in our lives, and the Internet has become an important helper in people's daily life. The information age has many characteristics, including high speed, multimedia, interactivity, anonymity, personality, digitization, asynchrony, upgradeability, openness, spontaneity, etc. With the rapid development of information technology and information, the activities closely related to the continually deepening, the characteristics of the information age are mainly divided into:

Information culture leads the era of social progress. In recent years, information culture has become the mainstream culture of the society, and the network culture industry has developed rapidly. The rapid rise of online games, online animation, online music, online movies and so on [1] has greatly enhanced the overall strength of the cultural industry.

The information age is an era of information explosion. The Internet age is an era of information explosion and knowledge explosion. The outbreak of information has accelerated the frequency of thinking; the explosion of knowledge has increased the accumulation of knowledge. In the Internet age, the brain has evolved faster and faster. As people enter the Internet age, traditional cognition and thinking are no longer applicable to contemporary development, and virtual networks have gradually replaced traditional thinking and are changing people's thinking.

\section{New Challenges Faced by In-depth Counseling in Student Development Guidance in the Information Age}

\subsection{The Transcendence of the Student Prophet to the Teacher's Prophet}

In the traditional education mode, the educational resources are limited by time, environment, etc., the information mainly comes from the teachers, the teachers are the authors of the educational resources, and the teachers have the advantages of knowledge, teaching, classroom, communication, etc. The aspect is active, and the students are passive in interacting with the teacher. Similarly, counselors have the initiative in the process of student development guidance because they have information and resources. However, with the advent of the information age, the channels for students to obtain information are not limited to pure classrooms, and the source of access is no longer limited to teachers. Not only that, because after the " $95 \mathrm{~s}$ " and " 00 ", they gradually became the main members of the information age. They get faster information and get more ways. They can also become "experts" 
in a certain field if students are willing. . The ability of students to capture information even exceeds that of teachers. The openness of information in the information age makes the traditional position of teachers not exist. Similarly, in the traditional work of counselors, the focus is mostly on the management of students' specific affairs and life. With the comprehensiveness of the school website services, students can easily find the transaction points and processes, and the counselors in the student development guidance. The role is not unique, the school website discussion area, knowing, etc. can find the corresponding answer. This poses a challenge for counselors in depth counseling.

\subsection{Social Development Combined with Individual Needs}

How to combine social development with individual student needs is a question that counselors need to think about in the process of in-depth counselors. The difficulty encountered by counselors in in-depth counseling in the information age is that the contradiction between the social norm that is emphasized in the training mode of colleges and the personal standard presented in the process of student growth is intensified. Some non-mainstream information is transmitted through the Internet, which has an impact on students, making it easier for students to lose their way in a network full of values. Counselors need to screen this information and pass on the correct values through in-depth counseling channels. Students correctly understand their lofty ambitions and down-to-earth, and implement their lofty ambitions into practical actions, so that diligent learning can return to the essence of student development.

\subsection{Personalization and Diversified Needs}

In the process of traditional student development guidance, the focus of counselor's in-depth guidance is more on the solution of students' academic problems or to help students solve some practical difficulties, and more specific situations are focused on [3]. With the development of the information age, the requirements for instructors' in-depth counseling are gradually improved. Counselors are required to pay attention to the ideological changes, life, learning and other dynamics of college students. After deep contact with the students, they will conduct in-depth exchanges with students. In-depth guidance to help students integrate into university life and overcome difficulties. Because the "post-95" and "after 00" personalization is clear, the counselor should also provide personalized in-depth counseling. If you want to maximize the attention of the students, the counselor needs to choose different communication channels according to the situation. Thinking and Analysis of Deep Counseling Work in the Guidance of Student Development in the Information Age

\subsection{Attempts to Introduce Scientific Methods from the Perspective of Experience}

In-depth coaching requires not only professional knowledge as a background, but also a more scientific approach. We must actively carry out psychological health education and psychological counseling for college students, pay attention to cultivating the good psychological quality of college students, and guide the healthy growth of college students. Psychological assessment can help the counselor to understand the student's situation. More and more colleges and universities set up "psychological counseling stations". The professional teachers will generate detailed evaluation reports on the students' generated assessments, and then feedback to the counselors. The content basically covers various aspects such as optimistic hope, personality strength, gratitude and life satisfaction. Although the current evaluation methods still need to be further improved, the evaluation effect has played a positive role in understanding the status of students. It can not only assist students in developing education, but also provide reference for core literacy and comprehensive quality assessment. In addition, the results of psychological assessment can see students' interests, personality and potential. Counselors can establish the relevance of students' learning, development, career selection and student personality need through comparison and analysis of big data. Proper career planning, etc., make deep counseling more scientific. 


\subsection{From Solving a Single Problem to a Career Plan}

In the traditional student development counseling, the focus of the counselor's communication with the students is often academic, business or focus on a practical problem, and often "catch the middle of the two heads", so it is difficult to take care of each student's appeal, and on the matter The working methods are difficult to have a profound impact on students and give students a better understanding of the meaning of the university. Moreover, each student has different needs at different stages. Undergraduates in the lower grades may be concerned about the possibility of more attention to how to play campus, develop specialties, make friends, etc., and gradually transition to higher-level college students may pay more attention to postgraduate study, going abroad, The future development of employment.

Counselors should not only provide in-depth counseling based on individual needs, but also focus on different groups. For the freshman group of students, the counselor needs to help the students to better adapt to the new environment; for the sophomore group, more attention is paid to the students' academic and classmates' problems; for the juniors, the group begins. Students postgraduate studies and study abroad, and carry out further study guidance in advance, the employment group needs to conduct interview training, etc.; for the senior group, it is necessary to pay attention to the preparation of the deep-rooted group and the progress of the employment group. Recommend appropriate career plans to students, etc., to make deep counseling more scientific [2].

\subsection{Three-dimensional Integration of All-round Power on the Offline Line}

The Internet allows us to understand the latest developments of students and achieve "early discovery, early attention, early resolution" for students. Online communication can eliminate the formal and stereotyped feelings of face-to-face communication, allowing some students who are not well-informed to speak freely, since students I felt that being cared for and cared for brought the distance between each other and solved the problem of the students. Relying on various platforms of the network to carry out in-depth counseling, giving full play to the advantages of the platform, solving the inadequacy of in-depth counseling, and making the development guidance work more precise, is also the demand of the development of the times [4].

Counselors can use the network to guide students to use the network reasonably, learn to identify all kinds of information, and convey correct values and outlook on life. Counselors can open online public classes, WeChat public accounts, blogs, etc., through the use of American language sharing, learning analysis, and practical discussions to attract students with diverse and visual expressions, enhance the appeal, and truly play an active role in the development of students in the network. The role of students to participate more actively in various activities.

\section{References}

[1]. Li Shizhong, et al. Human beings are entering the "six first" information age [N]; learning time.

[2]. Gu Haiyan, et al. On the construction model of social network and online learning community [J]. Continuing Education Research. Vol.1(2016): p.13-15.

[3]. Qin Chengkuan, et al. Reflections on the in-depth counseling work of college counselors[J]. Science journal. Vol. 29(2015): p.68-69.

[4]. Li Xiaofeng, et al. Practice exploration and thinking of postgraduate in-depth counseling [J]. China Electric Power Education. Vol.5(2015): p.225-226. 